Ignatenko A. V., Svinarenko A. A., Mansarliysky V. F., Sakun T. N.

Odesa State Environmental University, 15, Lvovskaya str., Odesa, 65016

National Aviation University, 1, Liubomyra Huzara ave., Kiev, 03058

E-mail: ignatenkoav13@gmail.com

\title{
OPTIMIZED QUASIPARTICLE DENSITY FUNCTIONAL AND GREEN'S FUNCTIONS METHOD TO COMPUTING BOND ENERGIES OF DIATOMIC MOLECULES
}

\begin{abstract}
It is presented an advanced approach to computing the energy and spectral parameters of the diatomic molecules, which is based on the hybrid combined density functional theory (DFT) and the Green's-functions (GF) approach. The Fermi-liquid quasiparticle version of the density functional theory is modified and used. The density of states, which describe the vibrational structure in photoelectron spectra, is defined with the use of combined DFT-GF approach and is well approximated by using only the first order coupling constants in the optimized one-quasiparticle approximation. Using the combined DFT-GF approach to computing the spectroscopic factors of diatomic molecules leads to significant simplification of the calculation procedure and increasing an accuracy of theoretical prediction. As illustration, the results of computing the bond energies in a number of known diatomic molecules are presented and compared with alternative theoretical results, obtained within discrete-variational $X_{\alpha}$, muffin-tin orbitals and other methods.
\end{abstract}

\section{Introduction}

In this paper we study the problem of calculating the important spectroscopic characteristics of multielectron systems (atoms and molecules), namely, the spectroscopic factor. The spectroscopic factor is one of the most important characteristics of atomic and molecular systems and the precise information about it is very important for many applications [1-47].

In calculations based on the density functional theory (DFT) methods in the local density (LP) approximation, invariants have become widespread: discrete-variational $X_{\alpha}$ (DV- $X_{\alpha}$ ), muffin-tin orbitals (MTO) method in a version of the linear MTO method and localized orbitals, modified DV- $X_{\alpha}$ method with using a scheme of the transition state (TS) (see [1]). Although, in computational terms, these methods are highly economical, the error in calculating complex molecules based on them can reach several eV

In this paper we present an advanced approach to computing the spectroscopic factors of the diatomic molecules within the hybrid combined density functional theory (DFT) in the Fermi-liquid formulation and the Green's-functions (GF) approach to quantitative determination of the spectroscopic factors for some molecular systems. The approach is based on the Green's function method (Cederbaum-Domske version) [1,2] and Fermi-liquid DFT formalism [3-7] and using the novel effective density functionalb (see also [11-22]). It is important that the calculational procedure is significantly simplified with using the quasiparticle DFT formalism.

\section{Many-body theory}

As usually, introducing a field operator $\Psi(R, \theta, x)=\sum_{i} \phi_{i}(x, R, \theta) a_{i}(R, \theta) \quad$ with the Hartree-Fock (HF) one-particle functions $\phi_{i}$ $\left(\epsilon_{i}(R)\right.$ are the one-particle HF energies and $\mathrm{f}$ denotes the set of orbitals occupied in the HF ground state; $R_{0}$ is the equilibrium geometry on the HF level) and dimensionless normal coordinates $\mathrm{Q}_{s}$ one can write the standard Hamiltonian as follows [2,7]:

$$
H=H_{E}+H_{N}+H_{E N}^{(1)}+H_{E N}^{(2)},
$$




$$
\begin{gathered}
H_{E}=\sum_{i} \epsilon_{i}\left(R_{0}\right) a_{i}^{t} a_{i}+\frac{1}{2} \sum V_{i j k l}\left(R_{0}\right) a_{i}^{t} a_{j}^{t} a_{l} a_{k}- \\
-\sum_{i, j} \sum_{k \in f}\left[V_{i k j k}\left(R_{0}\right)-V_{i k k j}\left(R_{0}\right)\right] a_{i}^{t} a_{j} \\
H_{N}=\hbar \sum_{s=1}^{M} \omega_{s}\left(b_{s}^{t} b_{s}+\frac{1}{2}\right), \quad N_{k}^{0}(\epsilon)=\frac{1}{2 \pi \hbar} \int_{-\infty}^{\infty} d t e^{i \hbar^{-1}\left(\epsilon-\epsilon_{k}\right) t}\left\langle 0\left|e^{ \pm i \hbar^{-1} \tilde{H}_{0^{t}}}\right| 0\right\rangle \\
H_{E N}^{(1)}=2^{-1 / 2} \sum_{s=1}^{M}\left(\frac{\partial \epsilon_{i}}{\partial Q_{s}}\right)_{0}^{M}\left(b_{s}+b_{s}^{t}\right)\left[a_{i}^{t} a_{i}-n_{i}\right]+\quad+\sum_{s, s^{\prime}=1}^{M} \gamma_{s s^{\prime}}^{k}\left(b_{s}+b_{s}^{t}+\sum_{s=1}^{M} g_{s}^{k}\left(b_{s^{\prime}}+b_{s^{\prime}}^{t}\right)\right. \\
+\frac{1}{4} \sum_{i} \sum_{s, s^{\prime}=1}^{M}\left(\frac{\partial^{2} \epsilon_{i}}{\partial Q_{s} \partial Q_{s^{\prime}}}\right)_{0}^{t}\left(b_{s}+b_{s}^{t}\right)\left(b_{s^{\prime}}+b_{s^{\prime}}^{t}\right)\left[a_{i}^{t} a_{i}-n_{i}\right]_{i}= \pm \frac{1}{\sqrt{2}}\left(\frac{\partial \epsilon_{i}}{\partial Q_{s}}\right)_{0}, \quad \gamma_{s s^{\prime}}^{i}= \pm \frac{1}{4}\left(\frac{\partial^{2} \epsilon_{i}}{\partial Q_{s} \partial Q_{s^{\prime}}}\right) .
\end{gathered}
$$

To get function $N_{k}(\epsilon)$ one calculates the $H_{E N}^{(2)}=2^{-3 / 2} \sum \sum_{s=1}^{M}\left(\frac{\partial V_{i j k l}}{\partial Q_{s}}\right)_{0}\left(b_{s}+b_{s}^{t}\right)\left[\delta v_{1} a_{i}^{t} a_{j}^{t} a_{k} G F G_{k k^{\prime}}(\epsilon)\right.$ (see details in Refs. [1-7,31-35]: $\left.+\delta v_{2} a_{l} a_{k} a_{i}^{t} a_{j}^{t}+2 \delta v_{3} a_{j}^{t} a_{k} a_{l} a_{i}^{t}\right]+$

$$
G_{k k^{\prime}}(\epsilon)=-i \hbar^{-1} \int_{-\infty}^{\infty} d t e^{i \hbar^{-l} t}\left\langle\psi_{0}\left|T\left\{a_{k}(t) a_{k}^{t}(0)\right\}\right| \psi_{0}\right\rangle
$$

$+\frac{1}{8} \sum \sum_{s, s^{\prime}=1}^{M}\left(\frac{\partial^{2} V_{i j k l}}{\partial Q_{s} \partial Q_{s^{\prime \prime}}}\right)_{0}\left(b_{s}+b_{s}^{t}\right)\left(b_{s^{\prime}}+b_{s^{\prime}}^{t}\right.$ $\left[\delta v_{1} a_{i}^{t} a_{j}^{t} a_{k}+\delta v_{2} a_{l} a_{k} a_{i}^{t} a_{j}^{t}+2 \delta v_{3} a_{j}^{t} a_{k} a_{l} a_{i}^{t}\right]$

with $n_{i}=1(0), i \in f(i \notin f), \delta \sigma_{f}=1(0),(i j k l) \in \sigma_{f}$ , where the index set $v_{1}$ means that at least $\phi_{k}$ and $\phi_{l}$ or $\phi_{i}$ and $\phi_{j}$ are unoccupied, $v_{2}$ that at most one of the orbitals is unoccupied, and $v_{3}$ that $\phi_{k}$ and $\phi_{j}$ or $\phi_{l}$ and $\phi_{j}$ are unoccupied. The $\omega_{s}$ are the HF frequencies; $b_{s}, b_{s}^{t}$ are destruction and creation operators for vibrational quanta as

$$
\begin{aligned}
& Q_{s}=(1 / \sqrt{2})\left(b_{s}+b_{s}^{t}\right) \\
& \partial / \partial Q_{s}=(1 / \sqrt{2})\left(b_{s}-b_{s}^{t}\right)
\end{aligned}
$$

The interpretation of the above Hamiltonian and an exact solution of the one-body HF problem is given in refs. [1,-7]. The usual way is to define the HF-single-particle component $H_{0}$ of the Hamiltonian (4) is as in Refs. [1,4]. Correspondingly in the oneparticle picture the density of occupied states is given by
Choosing the unperturbed $H_{0}$ to be $H_{0}=\sum \epsilon_{i} a_{i}^{t} a_{i}+H_{N}$ one could define GF as

$$
\begin{aligned}
& G_{k k^{\prime}}^{O B}(t)= \pm \delta_{k k^{\prime}} i \exp \left[-i n^{-1}\left(\varepsilon_{k} \mp \Delta \varepsilon\right) t\right] . \\
& \cdot \sum_{n}\left|\left\langle\hat{n}_{k}\left|U_{k}\right| 0\right\rangle\right|^{2} \exp \left( \pm i n_{k} \cdot \hat{\omega}_{k} t\right)
\end{aligned}
$$

The direct method for calculation of $N_{k}(\in)$ as the imaginary part of the GF includes a definition of the vertical I.P. (V.I.P.s) of the reference molecule and then of $N_{k}(\in)$.

The zeros of the functions:

$$
D_{k}(\in)=\in-\left[\epsilon^{o p}+\Sigma(\in)\right]_{k},
$$

where $\left(\epsilon^{o p}+\Sigma\right)_{k}$ denotes the $k$-th eigenvalue of the diagonal matrix of the one-particle energies added to matrix of the self-energy part, are the negative V. I. P. 's for a given geometry. One can write $[2,4]$ :

$$
\begin{gathered}
(\text { V.I.P. })_{k}=-\left(\in_{k}+F_{k}\right), \\
F_{k}=\Sigma_{k k}\left(-(\text { V.I.P. })_{k}\right) \approx \frac{1}{1-\partial \Sigma_{k k}\left(\epsilon_{k}\right) / \partial_{\epsilon}} \Sigma_{k k}\left(\in_{k}\right)
\end{gathered}
$$


Expanding the ionic energy $E_{k}^{N-1}$ about the equilibrium geometry of the reference molecule in a power series of the normal coordinates leads to a set of linear equations for the unknown normal coordinate shifts $\delta Q_{S}$, and new coupling constants:

$$
\begin{gathered}
g_{1}= \pm(1 / \sqrt{2})\left[\partial\left(\epsilon_{k}+F_{k}\right) / \partial Q_{l}\right]_{0} \\
\gamma_{l l^{\prime}}= \pm\left(\frac{1}{4}\right)\left[\partial^{2}\left(\epsilon_{k}+F_{k}\right) / \partial Q_{l} / \partial Q_{l^{\prime}}\right]_{0}
\end{gathered}
$$

The coupling constants $g_{l}, y_{l l^{\prime}}$ are calculated by the well-known perturbation expansion of the self-energy part. One could write:

$$
\sum_{k k}^{(2)}(\epsilon)=\sum_{\substack{i, j \\ s \notin F}} \frac{\left(V_{k s i j}-V_{k s j i}\right) V_{k s i j}}{\epsilon+\epsilon_{s}-\epsilon_{i}-\epsilon_{j}}+\sum_{\substack{i, j \\ s \notin F}} \frac{\left(V_{k s i j}-V_{k s j i}\right) V_{k s i j}}{\epsilon+\epsilon_{s}-\epsilon_{i}-\epsilon_{j}}
$$

and the coupling constant $g_{l}$, are as [17]:

$$
g_{l} \approx \pm \frac{1}{\sqrt{2}} \frac{\partial \in_{k}}{\partial Q_{l}} \frac{1+q_{k}(\partial / \partial \in) \sum_{k k}\left[-(\text { V.I.P. })_{k}\right]}{1-(\partial / \partial \in) \sum_{k k}\left[-(\text { V.I.P. })_{k}\right]}
$$

The pole strength of the corresponding GF:

$$
\begin{gathered}
\rho_{k}=\left\{1-\frac{\partial}{\partial \in} \sum_{k k}\left[-(V . I . P .)_{k}\right]\right\}^{-1} ; 1 \geq \rho_{k} \geq 0, \\
g_{l} \approx g_{l}^{0}\left[\rho_{k}+q_{k}\left(\rho_{k}-1\right)\right] \\
g_{l}^{0}= \pm 2^{-1 / 2} \partial \in_{k} / \partial Q_{l}
\end{gathered}
$$

\section{Fermi-liquid quasiparticle density functional theory}

The quasiparticle Fermi-liquid version of the DFT $[3-8,31,36]$ is used to determine the coupling constants etc. The master equations can be obtained on the basis of variational principle, if we start from a Lagrangian of a molecule $L_{q}$. It should be defined as a functional of quasiparticle densities:

$$
v_{0}(r)=\sum_{\lambda} n_{\lambda}\left|\Phi_{\lambda}(r)\right|^{2},
$$

$$
\begin{gathered}
v_{1}(r)=\sum_{\lambda} n_{\lambda}\left|\nabla \Phi_{\lambda}(r)\right|^{2}, \\
v_{2}(r)=\sum_{\lambda} n_{\lambda}\left[\Phi_{\lambda}^{*} \Phi_{\lambda}-\Phi_{\lambda}^{*} \Phi_{\lambda}\right] .
\end{gathered}
$$

The densities $v_{0}$ and $v_{1}$ are similar to the HF electron density and kinetical energy density correspondingly; the density $v_{2}$ has no an analog in the HF or DFT theory and appears as result of account for the energy dependence of the mass operator $\Sigma$. A Lagrangian $L_{q}$ can be written as a sum of a free Lagrangian and Lagrangian of interaction: $L_{q}=L_{q}{ }^{0}+$ $L_{q}{ }^{i n t}$, where the interaction Lagrangian is defined in the form, which is characteristic for a standard DFT (as a sum of the Coulomb and exchange-correlation terms), but, it takes into account for a mass operator energy dependence of $\Sigma$ :

$$
L_{q}^{\mathrm{int}}=L_{K}-\frac{1}{2} \sum_{i, k=0}^{2} \int \beta_{i k} F\left(r_{1}, r_{2}\right) v_{i}\left(r_{1}\right) v_{k}\left(r_{2}\right) d r_{1} d r_{2}
$$

where $\mathrm{F}$ is an effective exchange-correlation interaction potential. The constants $\beta_{i k}$ are defined in Refs. [3-5]. The constant $\beta_{02}$ can be calculated by analytical way, but it is very useful to keep in mind its connection with a spectroscopic factor $F_{s p}[4,5]$ :

$$
F_{s p}=\left\{1-\frac{\partial}{\partial \in} \sum_{k k}\left[-(V . I . P .)_{k}\right]\right\}
$$

The new element is linked with using the DFT correlation Gunnarsson-Lundqvist, LeeYang-Parrr functionals (c.g.[12-16]).

The multiplier $\left[1-\sum_{2}\right]$ is easily calculated if the Gunnarsson-Lundqvist-like correlation potential is used as $\mathrm{V}_{\mathrm{XC}}$ and $\sum_{2}$ is determined as follows:

$$
\begin{aligned}
& \sum(r)=0,254 \rho(r)\left[0,328 \rho^{-2 / 3}(r)+\right. \\
& \left.+0,204 \rho^{-2 / 3}(r) /\left\{1+18,376 \rho^{1 / 3}(r)\right\}\right]
\end{aligned}
$$




\section{Results and conclusions}

Let us present the results of calculating the binding energies and equilibrium distances in molecules $\mathrm{N}_{2}, \mathrm{O}_{2}, \mathrm{~F}_{2}$ belonging to the class of complex from the point of view of taking into account the correlation effects. Effective approach to this topic can be performed within different versions of the standard DV approach such as: DV $-X_{\alpha}, \mathrm{DV}-X_{\alpha}$ ( TS), MTO (see Table 1, where experimental data are also presented for comparison).

Table 1

Bond energies $(\mathrm{eV})$ and equilibrium distances (a.u.): 1 - experiment; 2- DV- $X_{\alpha}, 3$ - DV$X_{\alpha}$-TS, 4- MTO, 5 - Green function approach, 6 - present work

\begin{tabular}{|r|c|c|c|c|c|c|}
\hline & $E_{B}$ & $R_{e}$ & $E_{B}$ & $R_{e}$ & $E_{B}$ & $R_{e}$ \\
\hline & \multicolumn{2}{|c|}{$N_{2}$} & \multicolumn{2}{|c|}{$O_{2}$} & \multicolumn{2}{|c|}{$F_{2}$} \\
\hline 1 & 9,91 & 2,07 & 5,22 & 2,28 & 1,67 & 2,68 \\
\hline 2 & 9,39 & 2,11 & 8,15 & 2,35 & 8,97 & 2,35 \\
\hline 3 & 10,86 & 2,11 & 4,14 & 2,33 & 3,54 & 2,61 \\
\hline 4 & 7,8 & 2,16 & 4,10 & 2,30 & 0,6 & 2,91 \\
\hline 5 & 9,99 & 2,11 & 3,78 & 2,33 & 3,21 & 2,6 \\
\hline 6 & 9,95 & 2,09 & 5,12 & 2,31 & 1,58 & 2,70 \\
\hline
\end{tabular}

As follows from the comparison of the energy values presented in Table 1 and the values of the molecular constants are sensitive to the calculation scheme. A more careful consideration of multiparticle correlation effects within the framework of this procedure leads to an improvement in the agreement between the calculation and experiment (in particular, this is observed for molecules; for there is some deterioration). The results obtained in this calculation are in slightly better agreement with experiment than the results of calculations in other versions of the DV method.

It can be concluded that the development of a more perfect than the existing methods to computing molecular constants may be associated with careful consideration of complex correlation effects, including manybody corrections. The one-quasiparticle representation used here can be taken as the zeroth one in one of the sophisticated versions of the many-body PT such as, for example, the Möller-Plesset PT (see e.g. [6]).

\section{References}

1. Köppel, H., Domcke, W., Cederbaum, L.S., Green's function method in quantum chemistry. Adv. Chem. Phys. 1984, 57, 59-132

2. Cederbaum, L., Domcke, W., On vibrational structure of photoelectron spectra by the Green's functions method. J.Chem. Phys. 1984, 60, 2878-2896.

3. Glushkov, A. An universal quasiparticle energy functional in a density functional theory for relativistic atom. Opt. and Spectr. 1989, 66(1), 31-36.

4. Glushkov, A.V. New approach to theoretical definition of ionization potentials for molecules on the basis of Green's function method. J. Phys. Chem. 1992, 66, 2671-2677.

5. Glushkov, A.V. Relativistic and correlation effects in spectra of atomic systems. Astroprint: Odessa, 2006.

6. Glushkov, A.V. Relativistic Quantum theory. Quantum mechanics of atomic systems. Astroprint: Odessa, 2008.

7. Ignatenko, A.V. and Lavrenko, A.P., Spectroscopic factors of diatomic molecules: optimized green's functions and density functional method. Photoelectronics. 2019. Vol.28. P.83-89.

8. Ignatenko, A.V., Glushkov, A.V., Lepikh, Ya.I., Kvasikova, A.S. Photoelectron spectroscopy of diatomic molecules:optimized Green's functions and density functional approach. Photoelectronics. 2018, 27, 44-51.

9. Glushkov A., Khetselius O., Svinarenko A., Buyadzhi V. Spectroscopy of autoionization states of heavy atoms and multiply charged ions. TEC, 2015. 
10. Ponomarenko, E.L., Kuznetsova, A.A., Dubrovskaya, Yu.V., Bakunina, E.V. Energy and spectroscopic parameters of diatomics within generalized equation of motion method. Photoelectronics. 2016, 25, 114-118.

11. Svinarenko, A.A., Glushkov, A. V., Khetselius, O.Yu., Ternovsky,V.B., Dubrovskaya, Yu., Kuznetsova, A., Buyadzhi, V. Theoretical spectroscopy of rareearth elements: spectra and autoionization resonances. Rare Earth Element, Ed. J. Orjuela (InTech) 2017, pp 83-104

12. Glushkov, A.V., Khetselius, O.Yu., Svinarenko A.A., Buyadzhi, V.V., Ternovsky, V.B, Kuznetsova, A., Bashkarev, P Relativistic perturbation theory formalism to computing spectra and radiation characteristics: application to heavy element. Recent Studies in Perturbation Theory, ed. D. Uzunov (InTech) 2017, 131-150.

13. Kobayashi, K., Kurita, N., Kumahora, H., Kuzatami, T. Bond-energy calculations of $\mathrm{Cu}, \mathrm{Ag}, \mathrm{CuAg}$ with the generalized gradient approximation. Phys.Rev.A. 1991, 43, 5810

14. Lagowscki, J., Vosko, S. Analysis of local and gradient-correction correlation energy functionals using electron removal energies. J. Phys.B: At. Mol. Opt. Phys. 1988, 2l(1), 203-208.

15. Guo, Y., Whitehead, M. Effect of the correlation correction on the ionization potential and electron affinity in atoms. Phys.Rev.A. 1989, 39(1), 28-34.

16. Khetselius, O.Yu., Lopatkin Yu.M., Dubrovskaya, Yu.V, Svinarenko A.A. Sensing hyperfine-structure, electroweak interaction and parity non-conservation effect in heavy atoms and nuclei: New nuclear-QED approach. Sensor Electr. And Microsyst. Techn. 2010, 7(2), 11-19.

17. Florko, T., Ambrosov, S., Svinarenko A., Tkach, T. Collisional shift of the heavy atoms hyperfine lines in an atmosphere of the inert gas. J. Phys: Conf. Ser. 2012, 397(1), 012037.

18. Khetselius, O. Relativistic perturbation theory calculation of the hyperfine struc- ture parameters for some heavy-element isotopes. Int. J. Quant. Chem. 2009, 109, 3330-3335.

19. Khetselius, O. Relativistic calculation of the hyperfine structure parameters for heavy elements and laser detection of the heavy isotopes. Phys. Scr. 2009, 135, 014023.

20. Glushkov A.V., Atom in electromagnetic field. KNT: Kiev, 2005.

21. Khetselius, O. Yu. Hyperfine structure of atomic spectra; Astroprint: Odessa, 2008.

22. Khetselius, O.Yu. Quantum structure of electroweak interaction in heavy finite Fermi-systems. Astroprint: Odessa, 2011.

23. Khetselius, O.Y.., Glushkov, A.V., Gurskaya, M.Y., Kuznetsova, A.A., Dubrovskaya, Yu.V., Serga, I.N., Vitavetskaya, L.A. Computational modelling parity nonconservation and electroweak interaction effects in heavy atomic systems within the nuclear-relativistic manybody perturbation theory. J. Phys.: Conf. Ser. 2017, 905(1), 012029.

24. Glushkov, A., Gurskaya, M., Ignatenko, A., Smirnov, A., Serga, I., Svinarenko, A., Ternovsky, E. Computational code in atomic and nuclear quantum optics: Advanced computing multiphoton resonance parameters for atoms in a strong laser field. J. Phys.: Conf. Ser. 2017, 905(1), 012004.

25. Ambrosov S., Ignatenko V., Korchevsky D., Kozlovskaya V. Sensing stochasticity of atomic systems in crossed electric and magnetic fields by analysis of level statistics for continuous energy spectra. Sensor Electr. and Microsyst. Techn. 2005, Issue 2, 19-23.

26. Buyadzhi, V.V., Glushkov, A.V., Mansarliysky, V.F., Ignatenko, A.V., Svinarenko, A. Spectroscopy of atoms in a strong laser field: new method to sensing ac stark effect, multiphoton resonances parameters and ionization cross-sections. Sensor Electr. and Microsyst. Techn. 2015, 12(4), 27-36.

27. Svinarenko A.A., Mischenko E., Loboda A., Dubrovskaya Yu. Quantum measure of frequency and sensing the collisional 
shift of the ytterbium hyperfine lines in medium of helium gas. Sensor Electr. and Microsyst. Techn. 2009, 1, 25-29.

28. Malinovskaya S.V., Dubrovskaya Yu.V., Zelentzova T.N. The atomic chemical environment effect on the $b$ decay probabilities: Relativistic calculation. Herald of Kiev Nat. Univ. Ser.: Phys.-Math. 2004, N4, 427-432.

29. Glushkov A., Khetselius O., Svinarenko A., Prepelitsa G., Mischenko E., The Green's functions and density functional approach to vibrational structure in the photoelectron spectra for molecules. AIP Conf. Proc. 2010, 1290, 263-268.

30. Khetselius O., Florko T., Svinarenko A., Tkach T. Radiative and collisional spectroscopy of hyperfine lines of the Li-like heavy ions and $\mathrm{Tl}$ atom in an atmosphere of inert gas. Phys.Scripta. 2013, T153, 014037.

31. Glushkov, A.V., Kivganov, A.F., Khokhlov, V.N., Buyadzhi, T.V., Vitavetskaya, L.A., Borovskaya, G.A., Polishchuk, V.N. Calculation of the spectroscopic characteristics of diatomic van der Waals molecules and ions: Inert gas atom-halogen-type inert gas ion in the ground state. Russian Phys. Journ. 1998, 41(3), 223-226

32. Glushkov, A., Malinovskii, A., Efimov, V., Kivganov, A., Khokhlov, V., Vitavetskaya, L., Borovskaya, G., Calculation of alkaline metal dimers in terms of model perturbation theory. J. Struct. Chem. 1998, 39(2), 179-185.

33. Khetselius, O.Yu. Hyperfine structure of radium. Photoelectron. 2005, 14, 83-85

34. Khetselius O.Yu., Quantum Geometry: New approach to quantization of the quasistationary states of Dirac equation for super heavy ion and calculating hyper fine structure parameters. Proc. Int. Geometry Center. 2012, 5(3-4), 39-45.

35. Dubrovskaya, Yu., Khetselius, O.Yu., Vitavetskaya, L., Ternovsky, V., Serga, I. Quantum chemistry and spectroscopy of pionic atomic systems with accounting for relativistic, radiative, and strong in- teraction effects. Adv. in Quantum Chem. 2019, Vol.78, pp 193-222.

36. Khetselius, O.Yu., Glushkov, A.V., Dubrovskaya, Yu.V., Chernyakova, Yu.G., Ignatenko, A.V., Serga, I.N., Vitavetskaya, L. Relativistic quantum chemistry and spectroscopy of exotic atomic systems with accounting for strong interaction effects. In: Wang YA, Thachuk M, Krems R, Maruani J (eds) Concepts, Methods and Applications of Quantum Systems in Chemistry and Physics. Springer, Cham, 2018; Vol. 31, pp. 71-91.

37. Glushkov, A.V., Ivanov, L.N. Radiation decay of atomic states: atomic residue polarization and gauge noninvariant contributions. Phys. Lett. A 1992, 170, 33.

38. Glushkov, A.V.; Ivanov, L.N. DC strongfield Stark effect: consistent quantummechanical approach. J. Phys. B: At. Mol. Opt. Phys. 1993, 26, L379-386.

39. Ivanova, E., Glushkov, A. Theoretical investigation of spectra of multicharged ions of F-like and Ne-like isoelectronic sequences. J. Quant. Spectr. and Rad. Tr. 1986, 36(2), 127-145.

40. Ivanova, E.P., Ivanov, L.N., Glushkov, A., Kramida, A. High order corrections in the relativistic perturbation theory with the model zeroth approximation, $\mathrm{Mg}$ Like and Ne-Like Ions. Phys. Scripta 1985, 32, 513-522.

41. Glushkov, A.V. Multiphoton spectroscopy of atoms and nuclei in a laser field: Relativistic energy approach and radiation atomic lines moments method. Adv. in Quantum Chem. 2019, 78, 253-285.

42. Glushkov, A.V., Khetselius, O.Yu., Svinarenko, A.A., Buyadzhi, V. Methods of computational mathematics and mathematical physics. P.1. TES: Odessa, 2015.

43. Glushkov, A.V., Safranov, T.A., Khetselius, O.Yu., Ignatenko, A.V., Buyadzhi, V.V., Svinarenko, A.A. Analysis and forecast of the environmental radioactivity dynamics based on methods of chaos theory: General conceptions. Environm. Problems. 2016, 1(2), 115-120.

44. Glushkov, A., Buyadzhi, V., Kvasikova, 
A., Ignatenko, A., Kuznetsova, A., Prepelitsa, G., Ternovsky, V. Non-Linear chaotic dynamics of quantum systems: Molecules in an electromagnetic field and laser systems. In: Tadjer A, Pavlov R, Maruani J etal, (eds) Quantum Systems in Physics, Chemistry, and Biology. Springer, Cham. 2017, 30, 169

45. Robert, C., Morrison, R., Liu, G., Extended Koopmans theorem: approximate ionization energies from MCSCF Wave Functions. J. Comp. Chem. 1992, 13, 1004-1010.
46. Glushkov A.V., Khetselius O.Yu., Loboda A.V., Ignatenko A., Svinarenko A., Korchevsky D., Lovett L., QED Approach to Modeling Spectra of the Multicharged Ions in a Plasma: Oscillator and Electron-ion Collision Strengths.. AIP Conference Proceedings. 2008. 1058. 175-177

47. Svinarenko, A. Spectroscopy of autoionization resonancesin spectra of barium. Photoelectronics. 2014, 23, 86-90.

PACS 33.20.-t

Ignatenko A.V., Svinarenko A.A., Mansarliysky V.F., Sakun T.N.

\section{SPECTROSCOPIC FACTORS OF DIATOMIC MOLECULES: OPTIMIZED GREEN'S FUNCTIONS AND DENSITY FUNCTIONAL METHOD}

Summary. It is presented an advanced approach to computing the energy and spectral parameters of the diatomic molecules, which is based on the hybrid combined density functional theory (DFT) and the Green's-functions (GF) approach. The Fermi-liquid quasiparticle version of the density functional theory is modified and used. The density of states, which describe the vibrational structure in photoelectron spectra, is defined with the use of combined DFT-GF approach and is well approximated by using only the first order coupling constants in the optimized one-quasiparticle approximation. Using the combined DFT-GF approach to computing the spectroscopic factors of diatomic molecules leads to significant simplification of the calculation procedure and increasing an accuracy of theoretical prediction. As illustration, the results of computing the bond energies in a number of known diatomic molecules are presented and compared with alternative theoretical results, obtained within discrete-variational $X_{\alpha}$, muffin-tin orbitals and other methods.

Key words: diatomic molecules, Green's functions, density functional

PACS 33.20.-t

Игнатенко А.В., Свинаренко А.А., Мансарлийский В.Ф., Сакун Т.Н.

\section{ОПТИМИЗИРОВАННЫЙ МЕТОД ФУНКЦИОНАЛА ПЛОТНОСТИ И ФУНКЦИЙ ГРИНА В РАСЧЕТАХ ЭНЕРГИИ СВЯЗИ ДВУХАТОМНЫХ МОЛЕКУЛ}

Резюме. Представлен усовершенствованный подход к вычислению энергетических и спектральных параметров двухатомных молекул, базирующийся на гибридной комбинированной теории функционала плотности (ТФП) и методе функций Грина (ФГ). Используется модель ферми-жидкостная квазичастичная версия ТФП. Плотность состояний, которая описывает колебательную структуру в фотоэлектронных спектрах, определяется с использованием комбинированного подхода ТФП - ФГ. Использование комбинированного ТФП-ФГ подхода приводит к значительному упрощению процедуры расчета и повышению точности теоретического прогнозирования. В качестве иллюстрации представлены результаты расчета энергий связи в ряде известных двухатомных молекул, которые сравниваются с альтернативными теоретическими результатами, полученными с помощью дискретно-вариационного $X_{\alpha}$ и других подходов.

Ключевые слова: двухатомные молекулы, функция Грина, функционал плотности 
Ігнатенко Г.В., Свинаренко А.А., Мансарлійський В.Ф. , Сакун Т.М.

\section{ОПТИМІЗОВАНИЙ МЕТОД ФУНКЦІОНАЛУ ГУСТИНИ І ФУНКЦИЙ ГРІНА В РОЗРАХУНКАХ ЕНЕРГІЇ ЗВ'ЯЗКУ ДВОАТОМНИХ МОЛЕКУЛ}

Резюме. Представлений вдосконалений метод обчислення енергетичних та спектральних параметрів 2-атомних молекул, що базується на гібридній теорії функціонала щільності (ТФП) і методі функцій Гріна (ФГ). Використано фермі-рідинну квазічастинкову версію ТФП. Густина станів, які описує коливальну структуру фотоелектронного спектру, визначається в межах ТФП-ФГ методу. Використання комбінованого ТФП-ФГ методу призводить до спрощення процедури обчислень, підвищення точності прогнозу. В якості ілюстрації представлені результати розрахунку енергій зв'язку в ряді відомих двоатомних молекул, які порівнюються з альтернативними теоретичними результатами, отриманими за допомогою дискретно-варіаційного і інших підходів.

Ключові слова: двоатомні молекули, функція Гріна, функціонал густини. 